\title{
Federalismo cooperativo e Plano de Ações Articuladas (PAR) - Algumas aproximações teóricas ${ }^{1}$
}

Karla Cristina Silva Sousa ${ }^{a}$ Alda Maria Duarte Araújo Castro ${ }^{b}$

\section{Resumo}

$\mathrm{O}$ artigo discute o federalismo brasileiro a partir da matriz teórica self rule plus shared rule, ou seja, o federalismo enquanto pacto. Com base nessa matriz teórica, defende-se que a política educacional voltada para dinamizar o pacto federativo na área educacional por meio do regime de colaboração por ora denominada de Plano de Ações Articuladas (PAR) constitui-se, na realidade, um mecanismo de center constraining aos subgovernos nacionais em que a União situa-se como a grande demos constraining do federalismo brasileiro, caracterizando-se em um pacto incompleto.

Palavras-chave: Federalismo cooperativo. Plano de Ações Articuladas. Pacto federativo.

\section{Introdução}

A educação no Brasil é um direito subjetivo e está posta normativamente por meio da Constituição Federal de 1988. Sua operacionalização deve ocorrer por meio de um federalismo cooperativo que deve ser efetivado pelo regime de colaboração, conforme seu marco legal constitucional. Ao discutir a educação em um Estado federativo como o Brasil, deparamo-nos com um direito próprio das pessoas previsto em lei. A partir desse princípio, podemos questionar até que ponto esse direito está universalizado e se é alcançado pelas políticas educacionais, como o Plano de Ações Articuladas (PAR), elaborado para dar maior dinamicidade ao federalismo brasileiro ao se pautar no regime de colaboração entre os subgovernos nacionais.

\footnotetext{
${ }^{1}$ Esta pesquisa contou com financiamento Capes.

a Universidade Federal do Maranhão. São Luís, Maranhão, Brasil.

b Universidade Federal do Rio Grande do Norte. Natal, Rio Grande do Norte, Brasil. 
Com a institucionalização do Plano de Desenvolvimento da Educação (PDE), a intenção do Ministério da Educação (MEC) foi integrar um conjunto de programas para organizar melhor o sistema educacional, adotando uma visão sistêmica da educação, relacionando o ensino fundamental ao superior, incentivando a pesquisa e a remuneração de professores, dentre outras ações. O PDE tem como instrumento jurídico o PAR: um plano estrutural de longo prazo que visa a superar a fragmentação das políticas educacionais e a abrir diálogo entre os subgovernos nacionais, estabelecendo/fortalecendo o regime de colaboração. Dentro dessa proposição, os entes federados deveriam assumir as funções de gestão de políticas públicas fosse por iniciativa própria ou por adesão.

Com base nessa premissa, o artigo discute, na primeira seção, o federalismo a partir da matriz teórica de Elazar $(1987 ; 1994 ; 1995)$. Entende-se o federalismo como um pacto, uma forma de organização político-administrativa do território que conforma a necessidade de um compartilhamento horizontal de poder que mantém a estrutura nacional de uma democracia federativa, visto que o federalismo pensado enquanto pacto, conforme Elazar (1987), garantiria a estabilização dos processos decisórios entre os entes federados. Em seguida, destacamos o marco regulatório do federalismo no Brasil, a partir da Constituição de 1988 e suas implicações no modelo federalista brasileiro. O Brasil possui um modelo federalista que não se materializa nos aportes propostos por Elazar $(1987,1995)$ de federalismo cooperativo, nem nos modelos defendidos por Wright (1974; 1978) de autoridade interdependente, o que configura um federalismo incompleto.

$\mathrm{Na}$ terceira parte do artigo, o PAR é analisado como uma estratégia do governo federal para consolidar o regime de colaboração entre os entes federados e instituir o federalismo cooperativo previsto na Constituição Federal de 1988. Com o PAR, o Brasil procurou promover novos rumos do pacto federativo, composto pelo veto players (poder de veto) dos municípios brasileiros, agora entes federados com autonomia para instituir os seus próprios sistemas de ensino.

Com base nas matrizes teóricas apresentadas, pressupomos que o governo federal brasileiro não é demos constraining (democracia constrangida) em relação a seus subgovernos nacionais, o que o faz legislar, em primazia, políticas educacionais como o PAR, as quais interferem na gestão educacional dos subgovernos nacionais, transformando-os em meros executores. Nesse sentido, o PAR cerceia a autonomia destes e superimpõe a gestão por resultados como parâmetro para a melhoria da qualidade da educação. Os resultados da pesquisa sugerem que o PAR não efetiva a gestão por resultados, proposta em suas normativas legais, nem as Secretarias Municipais de Educação (Semeds) conseguem propor sua concepção de gestão educacional, 
criando um hibridismo que ora pende para o gerencialismo e performatividade, ora para a burocracia, ora para a total atuação descoordenada e desarticulada.

\section{O federalismo como sistema político: implicações no modelo brasileiro}

$\mathrm{O}$ federalismo desponta como uma forma político-administrativa mais adequada para organizar um Estado-Nação, tendo em vista que o compartilhamento de poder a não existência de níveis hierárquicos de decisão permitiriam reduzir as desigualdades sociais, estabelecendo relações de cooperação e solidariedade mais propícias a um regime democrático. Nesse sentido, existem dois conceitos que devem ser esclarecidos e que se confundem: o de federação e federalismo, fenômenos bem diferentes (COSTA, VMF, 2010). O federalismo seria a fórmula para a estabilização dos processos decisórios:

O federalismo é uma forma de associação política e de organização que une diferentes políticas dentro de um sistema político mais abrangente de tal forma que permite que cada membro mantenha sua própria integridade política. Sistemas federativos fazem isso ao requerer que as políticas básicas sejam feitas e implementadas através de alguma forma de negociação, de maneira que todos os membros possam compartilhar o processo de produção e execução das decisões (ELAZAR, 1995, p. 1, tradução nossa).

Na história da sociedade moderna, o federalismo terá seus aportes na Constituição Americana que instituiu nos Estados Unidos da América o federalismo como forma de governo que garantiria a unidade daquele país (COSTA, 2010). Em obra clássica, intitulada de O Federalista, Hamilton, Madison e Jay (2003) defendem a necessidade de um novo modelo federalista, negando o modelo de confederação. Os autores advogam o mesmo entendimento de Burgess (2006) e Elazar (1987) propondo a necessidade da divisão dos poderes em um regime federalista, pois a centralização seria prejudicial. Uma república federativa seria "a reunião de sociedades diferentes, ou a associação de um ou de muitos Estados debaixo de um só governo; porém, a extensão e as modificações desse governo e os objetivos submetidos à sua autoridade são coisas puramente arbitrárias" (HAMILTON, MADISON; JAY, 2003, p. 57). Segundo os autores, em um regime federalista a separação dos três poderes é importante para uma melhor organização desse regime. Citam o princípio dos freios e contrapesos (checks and balances) ultrapassando a ideia simplista da separação de funções, concebendo uma relação intercalada e sobreposta deles. 
Ao partir do princípio da repartição de poder (sharing of powers), o federalismo teria criado, segundo Riker (1964), um governo adicional. A questão é apontada pelo autor ao examinar o pensamento contido na obra intitulada $\mathrm{O}$ Federalista. A divisão de poderes acabava por instituir um Estado com duas matrizes interligadas: uma horizontal e outra vertical. No princípio da horizontalidade estariam contidos poderes distintos com funções distintas: Executivo, Legislativo e Judiciário. No polo da verticalidade há a presença dos entes federados que irão possuir poderes diferentes pelo princípio da territorialidade: União (poder federal) e Estados (poderes subnacionais ou poderes locais). A estrutura básica do modelo federativo, segundo o modelo matricial, está na distribuição do poder entre os vários centros, caracterizando-o como regime consensual de democracia. Sua essência está na divisão e distribuição do poder político (LIJPHART, 1999).

Na literatura internacional, encontramos em Wright (1978) um estudo sobre o federalismo americano, no qual o autor considera insuficiente a noção juridicista do federalismo e propõe, como referência de análise da dimensão territorial da ação estatal, o conceito de Intergovernmental Relations (IGR). O autor sugere três tipos de relações intergovernamentais, isto é, de coordenação federativa: o primeiro modelo proposto por Wright (1978) seria a autoridade independente ou separada em que as funções são delimitadas, não havendo interlocução entre as partes, nem coordenação. Constitucionalmente, nesse modelo, só são reconhecidos os governos federal e estadual, prevalecendo a independência entre eles. Os poderes locais estariam condicionados ao bem-querer do poder central, dependendo para seu funcionamento dos governos estaduais. Wright (1978) afirma a existência de um segundo tipo de IGR baseado no modelo de autoridade interdependente, no qual haveria a interseção entre duas ou mais esferas que poderiam atuar simultaneamente, produzindo complexas relações organizacionais. Nesse caso, um ente federado limita o poder de atuação do outro (checks and balances), tornando a barganha política através de acordos intergovernamentais e arranjos federativos essenciais para o movimento do padrão de autoridade (RIKER, 1964).

O último seria o modelo inclusivo. Segundo Wright (1978), na autoridade inclusiva, a atuação da unidade subnacional depende das decisões do governo federal; a relação é hierárquica, sendo o modo de interação entre os governos subnacionais uma extensão administrativa do governo federal. $\mathrm{O}$ aumento e a manutenção do poder central sobre os outros níveis de governos seriam dados a partir do jogo de soma zero (RODDEN, 2004). Aqui as subunidades não teriam a capacidade de exercer sua autoridade na tomada de decisão, tendo uma coordenação marcada por uma hierarquia vertical. 
Em termos de federalismo, Pierson (2000) destaca que é preciso observar a dimensão temporal dos eventos políticos, ou seja, a trajetória dependente de uma política (path dependence). Esse aspecto é relevante porque o Estado não seria um agente neutro e teria em suas instituições fatores históricos que modificam comportamentos coletivos. O Brasil por todo o século XX foi marcado - pela predominância em suas relações intergovernamentais, bem como seu modelo federalista - pelo crescimento da força política e econômica do governo federal, em relação aos governos estaduais. O isolamento do federalismo brasileiro cessou em 1930, quando o Brasil lançou seu projeto para a criação de uma sociedade urbano-industrial em que o Estado era o ator principal nas questões socioeconômicas e políticas. Na ditadura Vargas (1937-1945), o governo federal se empenhou para conseguir hegemonia perante os estados. Somente com o novo governo instituído com a constituição de 1946 é que o Brasil inicia a adoção de um federalismo mais cooperativo, baseado na partilha de receitas entre os níveis de governo (SOUZA, 1997).

Um conjunto de trajetória dependente está localizado no período de 1946-1964 em que o Estado desenvolvimentista dispõe de recursos suficientes para ostentar uma política clientelista em relação aos estados e municípios, configurando um modelo de democracia que restringe o poder-demos constraining - (STEPAN, 1999), muito embora o processo de formação de coalizões estáveis tenha sido variável conforme o mandato presidencial. Souza (2006) observa que esse período será permeado pela Constituição Federal de 1946, a qual estabelece a dimensão jurídico-institucional do federalismo, ocorrendo a criação de partidos nacionais e a ampliação da participação eleitoral. Esses dois destaques farão com que as relações entre poderes locais e governo federal sejam redefinidas nas arenas decisórias, impondo a participação e a representação política.

O outro período de trajetória dependente dar-se-á entre 1964-1985, em pleno regime militar, caracterizado por um modelo federalista marcado pela reforma tributária empreendida de 1965-1966 (ARRETCHE, 2004), fase conhecida como o grande ciclo de centralização, havendo uma troca na autoridade tributária, bem como na autonomia de gastos dos poderes locais sobre os recursos recebidos. A conjuntura será também denominada de federalismo de integração, visto que, nos documentos oficiais da época, essa nomenclatura era sobressaliente, composta por uma representação política que privilegiava o voto interiorano e rural "e pela introdução de eleições indiretas" (DUARTE, 2003, p.66). Sabemos que a integração expressava as teses da doutrina militar de segurança nacional que serviram de base para o estado de exceção, conhecido como regime militar. Baseado na doutrina de integração, o regime perseguiu todos os que eram contrários a essa ideologia. Integração nos documentos militares significava, na realidade, o combate ao comunismo e a todos aqueles que não concordavam com o regime. 
De 1985 a 1995 os governos estaduais alcançam o poder de veto com o modelo federalista estadualista, ou, como denominam Abrucio (1998) e Sano (2008), ultrapresidencialismo estadualista. Nesse federalismo, segundo os autores, predominam os interesses dos governadores estaduais e municipais. O último período em destaque de trajetória dependente se dá por ocasião da constituinte de 1988, que instaura uma reforma política sem precedentes na história brasileira. Apesar do novo contexto, parece que os mecanismos de outrora foram continuados, não propiciando a resolução dos dilemas intergovernamentais do federalismo no Brasil. Os direcionamentos advindos da Constituição Federal de 1988 impactarão o federalismo brasileiro, questões que passaremos a abordar na seção seguinte.

\section{A Constituição Federal de 1988 e o redimensionamento das questões federativas do Brasil - marcos regulatórios}

Arretche (1996) destaca que após a Constituinte de 1988, o Brasil retoma suas bases de Estado federado com um intenso processo de descentralização fiscal que mudará as relações intergovernamentais, fazendo as parcelas dos tributos repassados pela União aumentarem de forma significativa:

A descentralização e as mudanças realizadas no federalismo brasileiro não trouxeram apenas aspectos positivos em seu bojo. Os atores governamentais que mais se fortaleceram ao início foram os governos estaduais, os quais montaram, no vácuo deixado pelo Estado nacional-desenvolvimentista e na ausência de um novo projeto hegemônico, um federalismo estadualista (ABRUCIO; COSTA, 1998, p. 101).

No Brasil, as relações federalistas foram movidas por um contínuo, saindo do federalismo isolado, passando pela centralização até chegar ao federalismo atual mais descentralizado em termos constitucionais. Nunca uma ruptura geral, mas, sim, processual, "a Constituição Federal de 1988 instituiu um sistema legal de repartição de receitas que limita a capacidade de gasto do governo federal e, por consequência, sua capacidade de coordenação de políticas" (ARRETCHE, 2004, p. 17). Aos poucos, o processo decisório, os conflitos e alianças propiciados em 1988 foram favorecendo a consolidação da democracia e tornando o Brasil mais federal, ante a existência de vários poderes soberanos competidores entre si.

A constituição promulgada em 5 de outubro de 1988 traz em seu artigo $1^{\circ}$ a relação direta entre República Federativa e o estado de direito democrático: "A República 
Federativa do Brasil, formada pela união indissolúvel dos Estados e do Distrito Federal, constitui-se em um Estado Democrático de Direito" (BRASIL, 2005, p.19). O caráter federativo e autônomo dos municípios, no cenário brasileiro, está assegurado pelo artigo 18 da Carta Magna de 1988, descentralizando a política constitucional e criando três esferas de poder (federal, estadual e municipal). Em nenhuma outra nação o município será reconhecido constitucionalmente enquanto ente federado. Esta peculiaridade confere aos municípios do Brasil sua autonomia político-administrativa, instalando, talvez, o modelo federalista cooperativo (ELAZAR, 1987; 1995) ou o modelo de autoridade interdependente (WRIGHT, 1978).

No intuito de manter os valores democráticos, a nova Constituição inverteu o modelo anterior. A descentralização foi substituindo a centralização e transformando o Brasil em um Estado descentralizado no tangente a distribuição de recursos e veto players (decisão política). Isso em nível de texto constitucional, pois a descentralização proposta pelo marco legal não se materializa na prática, quando pensamos, por exemplo, em políticas educacionais. O próprio PAR confirma que a descentralização não se efetiva como propõe a douta norma. Por esse motivo, nesta pesquisa ele se apresenta como center constraining (mecanismo de constrangimento) aos subgovernos (estados e municípios).

A descentralização reduziu a possibilidade de diminuir os desequilíbrios regionais, visto que, relativamente, o governo federal ficou um pouco enfraquecido, não significando que se tornou passivo ou ausente, mas tão somente forçado a negociar com as novas lideranças: governadores e prefeitos (SOUZA, 2001, ARRETCHE, 2000). Outra situação surge com a descentralização proposta pela Carta de 1988:

O municipalismo autárquico é outro elemento resultante da peculiar descentralização brasileira. Suas bases estão no discurso que reduziu a descentralização à municipalização. Logo, deveria ser constituído um modelo no qual cada município, independente de suas diferenças, deveria assumir todo o rol de políticas públicas que cabem a este ente federativo - aliás, a instituição do município como ente federativo, como fez a Constituição de 1988, é algo incomum na experiência internacional (ABRUCIO; COSTA, 1998, p.102).

A idiossincrasia do federalismo no Brasil lembra-nos o alerta de Pierson (2000) para o fato de que a path dependence é algo diferente nos vários modelos de democracia. Lijphart (1999) - quando estuda os trinta e seis modelos de democracias - observa que em cada um a path dependence ou aquilo que ele denomina de patterns of democracy (modelos de democracias) será variado. O centralismo 
federativo brasileiro decorre, em parte, da interpretação e aplicação das normas constitucionais. A constituição brasileira de 1988 optou por um modelo que valoriza a fragmentação e amplia o número de atores políticos com poderes de contestação da tomada de decisão, o que gera no Brasil uma arena competitiva paralisada, na qual os atores podem-se cancelar mutuamente, surgindo um federalismo periférico (SOUZA, 1997).

No plano das relações verticais, o federalismo brasileiro não foi capaz de cumprir com um dos princípios observados por Elazar (1987): o compartilhamento em equilíbrio da tomada de decisão. Assemelha-se ao tipo de democracia denominada por Lijphart (1999) de majoritária. Coube à Constituinte de 1988 solucionar os dilemas do período anterior, aumentando a participação das esferas locais e diminuindo o poderio do governo central, sob o prisma da descentralização. A importância dos governos locais não é destaque somente na literatura nacional. Watts (1994) identificou que a relevância dos poderes locais nas federações foi ao longo do tempo aumentando, fazendo as federações mudarem suas estruturas tradicionais.

Por seus dispositivos legais instituídos nos artigos 18, 21, 22, 24, 24, 34 e 35, a autonomia dos três governos e suas relações intergovernamentais são bem definidas, não podendo, por exemplo, a União intervir na gestão de um município sem que esta ação esteja assegurada legalmente conforme prescreve a constituição. Os dispositivos citados são omissos em vários momentos. Uma das omissões está presente no artigo 24 que, ao prever a distribuição de competências legislativas, não cita o município na partilha de poder. Encontra-se no artigo citado a seguinte redação: "Compete à União, aos Estados e municípios legislar concorrentemente sobre: IX- educação, cultura, ensino e desporto; XV- proteção da infância e juventude" (BRASIL, 2005, p. 35). A omissão constitucional seria, na realidade, a hipótese em que o legislador disse menos do que realmente queria, visto que as palavras de uma constituição devem ser tomadas de forma natural e óbvia, evitando-se o alargamento ou restrição do seu significado (OLIVEIRA, 2010).

Esta dispersão de autoridade em países federalistas faz com que o conteúdo das decisões tomadas seja afetado em virtude dos interesses produzidos pelo governo federal (PIERSON, 2000). De 1991 a 1994, teremos acentuada fragilidade dos freios e contrapesos. A ausência de regulação por leis específicas no pacto federativo proposto pela Constituição de 1988, no tangente a mecanismos de cooperação eficientes, faz com que as relações intergovernamentais cooperativas sejam sacrificadas, reduzindo os canais de negociação que poderiam minimizar a competição (ABRUCIO, 2005; ARRECTHE, 2005; KUGELMAS; SOLA, 2000; SOUZA, 1997; 2005). 
Camargo (1993) destaca que, em momentos de crise, os conflitos federativos aumentam, havendo a necessidade de normas e mecanismos de controle que sejam aceitos por todos, visando ao bem comum. É preciso afastar o jogo da soma zero (HODDEN, 2004). A harmonia federativa deve ser pautada no seguinte princípio: todas as unidades federadas devem atuar mutuamente para a realização dos objetivos da república federativa. No caso do Brasil, deve-se cumprir o disposto artigo 3 da Constituição Federal de 1988:

Art. $3^{\circ}$ Constituem objetivos fundamentais da República Federativa do Brasil:

I - construir uma sociedade livre, justa e solidária;

II - garantir o desenvolvimento nacional;

III - erradicar a pobreza e a marginalização e reduzir as desigualdades sociais e regionais;

IV - promover o bem de todos, sem preconceitos de origem, raça, sexo, cor, idade e quaisquer outras formas de discriminação (BRASIL, 2005, p.19-20).

Este fundamento constitucional implica que as unidades da federação cooperem umas com as outras: é o princípio da solidariedade. Este é o fundamento legal que normatiza toda a política educacional brasileira. Há a previsão, por parte da União, de complementações e transferências de recursos entre os subgovernos, inclusive de município para município. A União tem o papel de promover a equalização e redistribuição de recursos, mantendo a federação equilibrada.

$\mathrm{Na}$ área educacional, Arretche (2002) mostra que o governo federal irá encontrar resultados diversos na implantação das reformas que afetavam os interesses dos estados e municípios, fazendo com que o veto players destes entes não fosse de todo utilizado. Os subgovernos nacionais não foram capazes de transpor seu poder de veto na Reforma Educacional no ano de 1990. No poder de veto brasileiro, os municípios "não representaram um ponto de veto intransponível à implementação da agenda de reformas do governo federal nessas políticas particulares"(ARRETCHE, 2002, p.433).

Constitucionalmente, a educação será observada, sob normas privativas, ora concorrentes, ora comuns no estabelecimento das diretrizes e bases da educação: "Art. 22. Compete à União legislar sobre: XXIV - Diretrizes e bases da educação nacional; Parágrafo único. Lei complementar poderá autorizar os Estados a legislar sobre questões específicas das matérias relacionadas neste artigo" (BRASIL, 2005 , p. 34). O problema de federalismo fiscal, ou a falta de um modelo para este, 
reproduz no regime de colaboração o desequilíbrio federativo. Como Abrucio e Costa (1998) previram, o caso brasileiro é materializado por um frágil contrato federativo baseado no modelo predatório e não cooperativo, não caracterizando o federalismo proposto em Dye (1990), baseado na competição de Wright (1978) e seu modelo de autoridade interdependente, ou mesmo no modelo cooperativo de Elazar (1987), justificado pela competição coordenativa.

A autonomia conferida aos municípios na Carta de 1988, a partir da Reforma do Estado, será entendida como descentralização das responsabilidades, mas não dos recursos, fazendo o Brasil adotar a postura de Estado gerencial, cujos aportes passaremos a discutir a partir da análise do Plano de Ações Articuladas (PAR) enquanto proposta do governo federal para um federalismo cooperativo. Constatamos, por meio das análises apresentadas até aqui, que o federalismo brasileiro não se materializa nos aportes de Elazar (1987) de autogoverno e autocompartilhamento (self rule plus shared rule), nem nos de Wright (1978), quando propõe a autoridade interdependente. Este quadro de federalismo de coalização, dependente e centralizador, possui continuidade por meio das políticas educacionais adotadas no governo do ex-presidente Luiz Inácio da Silva (2003-2010), conforme os argumentos expostos a seguir.

\section{Federalismo e Plano de Ações Articuladas (PAR): novos rumos do federalismo no Brasil?}

No federalismo brasileiro o regime de colaboração é entendido como possibilitador da qualidade da educação básica. A Constituição de 1988 reluta em criar um Sistema Nacional de Educação e acaba pluralizando os sistemas a partir do art. 211, deixando a Lei de Diretrizes e Bases da Educação Nacional (LDBEN) nº 9.394/1996 (BRASIL, 1996) normatizar essa questão. No tangente aos dilemas advindos dos recursos orçamentários, a Constituição, ao incorporar o município à federação enquanto ente federado, mostrou o descompasso dos recursos disponibilizados para os governos subnacionais e suas responsabilidades de oferta, mesmo tendo como base as transferências intergovernamentais.

Importante assinalar que, para o governo do ex-presidente Fernando Henrique Cardoso (1995-2002), o modelo de gestão do federalismo brasileiro adotado pela Constituição de 1988 orientou-se por uma concepção de administração pública verticalizada, hierárquica e rígida que "favorece a proliferação de controles muitas vezes desnecessários” (BRASIL, 1995).

Sob o argumento de superar essa verticalização do regime de colaboração na educação, o governo federal aprovou o Plano Nacional de Educação (PNE). O PNE (2001-2010) 
foi proposto pelo Congresso Nacional em 2000 e sancionado pelo governo federal no ano de 2001, convertido na Lei $\mathrm{n}^{\circ}$ 10.172/2001 (BRASIL, 2001). Suas origens são marcadas por discussões entre duas versões distintas: uma vinda do poder executivo e legislativo, e a outra, da participação popular organizada em fóruns nacionais.

O PNE enfatizava serem de responsabilidade dos municípios a oferta e garantia da educação infantil e do ensino fundamental, colocando uma atuação subsidiária da União e estados. Definindo seu posicionamento de Estado avaliador quando normatiza no art. $3^{\circ}$ que procederá avaliações periódicas para a implantação do plano, demonstrando que o regime de colaboração na educação brasileira é um pacto incompleto.

O PNE centralizou a tomada de decisão quando o mesmo artigo, $\S 2^{\circ}$, resguarda à União o direito de baixar medidas legais para eventuais deficiências ou distorções, denotando um federalismo de coalização (dependente e predatório), conforme caracterizou Riker (1964) em seus estudos sobre os tipos de federalismos praticados em vários países. O Estado avaliador se destaca no texto do PNE da seguinte maneira: “Art. 4". A União instituirá o Sistema Nacional de Avaliação e estabelecerá os mecanismos necessários ao acompanhamento das metas constantes do Plano Nacional de Educação" (BRASIL, 2001).

Tentando superar os dilemas do federalismo brasileiro dentro do campo educacional, o governo federal lançou no ano de 2007 o PDE, cujo aporte teórico está ligado a um modelo sistêmico de educação e de planejamento, apontando a ruptura necessária com o modelo anterior de educação estabelecido no Brasil. O plano aliou-se ao conjunto de políticas sociais que dariam dinamicidade ao novo modelo de desenvolvimento perquirido pelo governo do ex-presidente Luís Inácio da Silva (MINEIRO, 2010). O contexto de criação do PDE advém de um estudo realizado no ano de 2006 pelo Fundo das Nações Unidas para a Infância (Unicef), que elegeu o tema aprender como central para o desenvolvimento de seus trabalhos no Brasil.

O PDE tem como instrumento jurídico o PAR, normatizado pelo Decreto $\mathrm{n}^{\mathrm{o}}$ 6.094/2007, sendo definido da seguinte forma: “Art. 9. O PAR é o conjunto articulado de ações, apoiado técnica ou financeiramente pelo Ministério da Educação, que visa ao cumprimento das metas do Compromisso e a observância das suas diretrizes" (BRASIL, 2007a). O Plano de Ações Articuladas constitui-se em um plano estrutural de longo prazo que visa a superar a fragmentação das políticas educacionais e a abrir o diálogo entre os entes federados, estabelecendo/fortalecendo o regime de colaboração. Possui em seu texto a pretensão de promover a gestão democrática da educação, reunindo indicadores que contribuem para uma análise da qualidade da educação nos subgovernos nacionais. 
O PAR estava previsto para ser implantado nos municípios selecionados com base no Índice de Desenvolvimento da Educação Básica (IDEB). Em 2005, houve a adesão de 1.242 municípios priorizados e, em 2007, foram contemplados 1.412 municípios que aderiram ao Compromisso Todos pela Educação (CTPE). Em 2010, mais de $90 \%$ dos municípios brasileiros já haviam sido contemplados com essa proposta que faz parte do PDE. No início de 2011, aderiram ao plano 5.495 municípios que assinaram o termo de cooperação técnica, oriundo do PAR com a União (BRASIL, 2007b).

Com o Plano de Ações Articuladas adentrou ainda mais na educação brasileira a concepção de accountability, ocorrendo a fragmentação do serviço educacional, entendida aqui como a introdução do gerencialismo local nas Semeds. A escola seria a responsável pela revolução da qualidade na educação, e as Semeds deveriam implementar as ações e subações do PAR, de modo a oferecer uma educação de qualidade balizada por uma gestão de resultados.

O Decreto $n^{\circ} 6.094 / 2007$ coloca o PAR como centro da agenda pública da política educacional brasileira, priorizando as ações baseadas no interesse coletivo dos municípios, considerando a realidade sistêmica desses. Pelo decreto, a participação na tomada de decisão é compartilhada por gestores escolares, Secretários de Educação, demais funcionários e sociedade civil. Trata-se de uma participação institucionalizada ao "promover a gestão participativa na rede de ensino" (Art. $2^{\circ}$, inciso XXII, BRASIL, 2007a). Na configuração do PAR, os sujeitos locais são conclamados à participação e responsabilizados por efetuar as ações que resultariam na melhoria da qualidade educacional. O plano altera os modos e modelos de gestão proferidos nas subunidades governamentais, ao estar estruturado em 04 (quatro) dimensões que lhe dão base:

1. Gestão educacional: está subdividida por meio do Guia Prático de Ações do Plano de Metas Compromisso Todos pela Educação em áreas (BRASIL, 2007b). As áreas são: área 1 - Gestão Democrática: articulação e desenvolvimento dos sistemas de ensino; área 2 - Desenvolvimento da educação básica: ações que visem à sua universalização, à melhoria da qualidade do ensino e da aprendizagem, assegurando a equidade nas condições de acesso e permanência e conclusão na idade certa; área 3 - Comunicação com a sociedade; área 4 - Suficiência e estabilidade da equipe escolar; área 5-Gestão de finanças.

2. Formação de professores e de profissionais de serviço e apoio escolar: possui as seguintes áreas: área 1 - Formação inicial de professores da educação básica; área 2 - Formação continuada de professores da educação básica; área 3 -Formação de professores da educação básica para atuação em educação especial, escolas 
do campo, comunidades quilombolas ou indígenas; área 4 - Formação inicial e continuada de professores da educação básica para o cumprimento da Lei $n^{\circ}$ 10.639/2003; área 5 - Formação de profissionais da educação (funcionários).

3. Práticas pedagógicas e avaliação: dividida em: área 1 - Elaboração e organização das práticas pedagógicas; área 2 - Avaliação da aprendizagem dos alunos e tempo para assistência individual/coletiva aos alunos que apresentam dificuldades de aprendizagens.

4. Infraestrutura física e recursos pedagógicos: divide-se em: área 1 - Instalações físicas gerais e equipamentos; área 2 - Integração e expansão do uso de tecnologias da informação e comunicação na educação pública.

O plano traz, por meio de suas ações e estratégias para cada dimensão, um modelo de política educacional baseado nos resultados, denominada por Ball (2001) de performatividade, possuindo conceitos como: resultado, níveis de desempenho e formas de qualidade. Prevê a responsabilização por meio da prerrogativa do regime de colaboração:

O Plano, a ser executado em regime de colaboração com Municípios e Unidades Federadas, buscando também a participação das famílias e da comunidade, envolve primordialmente a decisão política, a ação técnica e atendimento da demanda educacional, visando à melhoria dos indicadores educacionais (BRASIL, 2007c, p. 5).

O PAR é um plano executivo com discurso ambivalente que, de um lado, propõe o regime de colaboração e, de outro, condiciona a colaboração à mudança na gestão educacional proferida pelas Secretarias Municipais de Educação. As quatro dimensões do plano são a nova forma de estruturação requerida para as Secretarias Municipais de Educação como modelo de gestão da educação. A partir do PAR as secretarias devem modelar sua gestão educacional com base nas dimensões, áreas e estratégias previstas no guia prático de ações.

Como instrumento da gestão educacional, o PAR traz a concepção de gestão de resultados para a gestão pública: "O Ministério da Educação realizará oficinas de capacitação para a gestão de resultados, visando a instituir metodologias de acompanhamento adequada aos objetivos instituídos neste Decreto" (BRASIL, 2007a, Art. 11, $2^{\circ}$ ). O gerenciamento oriundo do mercado é importado para a educação brasileira por meio dessa política, colocando-se, sobre e contra o trabalho proferido nos sistemas educacionais dos entes federados, bem como das autoridades educacionais locais (Secretarias de Educação). 
O modelo de gestão adotado no PAR concebe o sistema de gestão proferido pelas Secretarias de Educação como pesado, impedidor do espírito empreendedor que os trabalhadores da educação possuem. Os gestores dos sistemas educacionais devem ser líderes, fornecendo visões que gerem um compromisso coletivo (CLARKE, NEWMAN, 1997; CLARKE et al., 1994). Este novo gerente da educação proposto pelo PAR deve promover uma tranquila implementação dos objetivos do plano, não cabendo questionar ou criticar as metas estabelecidas pelo Decreto $n^{\circ} 6.094 / 2007$, pois as decisões instrumentais são guiadas pela eficiência e pelo discurso de gestão por resultados, impondo uma racionalidade técnica. O discurso da participação é enfatizado do seguinte modo: "É fundamental lembrar que a realização do diagnóstico, bem como a elaboração do PAR são de caráter participativo e têm por objetivo promover uma análise compartilhada da situação educacional na rede municipal" (BRASIL, 2007d, p. 3).

As Secretarias Municipais de Educação devem obedecer a uma retórica de boa governança, eficiência e qualidade, baseada nos resultados do IDEB. As Semeds acabam escondendo os desfechos de um modelo federativo fragilizado, visto que a combinação particular de prioridades descritas no guia de ações é distinta das realidades regionais brasileiras. A arena política do PAR promove o governo indireto, envolve não só uma estrutura de responsabilidades, como também novas formas de controle e responsabilização (accountability). O MEC, enquanto seu idealizador, controla os subgovernos (que deveriam atuar com autonomia) por meio de arranjos contratuais denominados de Termos de Compromisso, a partir da Resolução n ${ }^{\circ}$ 14/2012 do Fundo Nacional de Desenvolvimento da Educação (FNDE):

III - aos Municípios, aos Estados e ao Distrito Federal:

[...]

e) aceitar o Termo de Compromisso com o respectivo cronograma de execução, no endereço eletrônico http://simec.mec.gov.br, utilizando a senha fornecida ao ente federado;

f) executar os recursos financeiros transferidos pelo FNDE/ MEC exclusivamente no cumprimento das ações pactuadas no Termo de Compromisso e dentro do cronograma estabelecido; (BRASIL, 2012).

O conceito de participação apresentado no Plano opera como uma espécie de controle das atividades públicas (AFFONSO, 2003). A participação no sentido de promover a democratização da educação envolve a formulação de políticas educacionais, a determinação de objetivos e fins da educação, bem como a definição sobre a alocação de recursos (MEDEIROS; LUCE, 2006), aspecto que o PAR 
desconsiderou ao chegar pronto para os municípios e estados apenas executarem. A participação pretendida pelo PAR é regulatória por entender a administração dos sistemas escolares a partir de rígidas normas, regras e procedimentos rigorosos de controle das atividades educacionais.

O PAR propaga um modelo teórico retórico de accountability cuja concepção ideológica e política subestima os subgovernos nacionais, descaracterizando seus sistemas educacionais enquanto instrumentos de legitimação de um regime de colaboração. Neste sentido, devemos observar que um regime federalista deve estabelecer claramente as formas de compartilhamento (ELAZAR, 1987; 1995).

Há no texto do PAR um entendimento de que o federalismo, baseado no regime de colaboração, é a forma mais eficiente para tratar os problemas de governabilidade existentes no Brasil. O Plano de Ações Articuladas seria, dentro da visão do governo federal, o modelo ideal de pacto federalista na educação quando propõe proteger as minorias. Ao mesmo tempo, força a maioria ao consenso: "O PAR será base para termo de convênio ou de cooperação, firmado entre o Ministério da Educação e o ente apoiado" (BRASIL, 2007a, Art. 10).

Constitui-se, na perspectiva da União, uma ferramenta fundamental para a devolução de autoridade aos subgovernos, por permitir a implementação de vários programas intergovernamentais. Por ser um plano sistêmico e estratégico, as ações da educação básica e superior se encontram no PAR. Caracteriza-se em uma associação para o desempenho (performance partnerships) entre os níveis de governo, prometendo ser um instrumento de transformação das relações intergovernamentais (que, no Brasil, ainda são problemáticas). Pierson (1996) argumenta que as instituições políticas dos países variam, com o passar do tempo, as regras do jogo. Segundo o autor, as instituições podem estabelecer as regras do jogo para as lutas políticas - influenciando as identidades de grupo, preferências políticas e escolhas de coalizão - e reforçam o poder de negociação de alguns grupos enquanto desvalorizam outros.

A matriz que prega a qualidade mensurada por meio de avaliações se propagou pelo mundo ocidental a partir de 1990, quando os Estados latino-americanos promovem a Reforma do Aparelho do Estado e da Educação, pautada nos anseios das organizações internacionais, cujo foco central é o desenvolvimento mundial. Os entes federados são conclamados a funcionar bem, com custos menores e resultados positivos. A gestão pública deve ser universal na prestação e igual no atendimento. $\mathrm{O}$ conceito de qualidade presente no PAR deve ser problematizado considerando as especificidades da educação brasileira, pois nele as Secretarias 
Municipais de Educação são responsabilizadas quanto à sua execução, não concretizando o federalismo cooperativo de fato.

Cabe assinalar, após nossas análises, que o modelo federalista de coalização, originado pela Constituição de 1988, está em crise, visto que o presidencialismo e as sub-representações apresentam aquilo que Wright (1978) denomina de autoridade dependente, ou seja, uma sub-representatividade das unidades da União nas composições da Câmara e do Senado, em que a desigualdade no número de assentos reproduz o desequilíbrio em nosso federalismo. Daí termos classificado (pelo menos a partir do nosso estudo) de pacto incompleto, ou jogo de soma zero, em que um dos lados sai perdendo, no caso os subgovernos nacionais.

\section{Considerações finais}

O federalismo, enquanto forma de organização política-administrativa, configura-se como uma opção para as democracias que querem instituir um modelo baseado no compartilhamento de poder e de tomada de decisões. O modelo cooperativo apresenta-se como propositivo no sentido de garantir as políticas de proteção social. O corpo político do federalismo é formado por uma associação voluntária de informações de indivíduos. É um contrato social em que todos os participantes serão governados por certas leis. Considerando estes princípios, observa-se que o federalismo brasileiro é marcado por um contínuo centralização/descentralização que prejudica a adoção de políticas educacionais baseadas em um federalismo cooperativo ou interdependente.

A Constituição Federal de 1988 é uma tentativa de promover o federalismo cooperativo ao instituir a descentralização das ações educacionais por meio do regime de colaboração, atribuindo autonomia aos municípios que passam a ser considerados entes federativos dotados de competências específicas. Apesar de a Constituição trazer como meta um federalismo cooperativo, o Brasil enfrenta dificuldades para sua implementação. Essa dificuldade foi ampliada após a reforma do Estado realizada no ano de 1996 pelo governo do ex-presidente Fernando Henrique Cardoso: promoveu um processo de descentralização das responsabilidades para com a educação básica, deixando estados e municípios com esta competência. Com o modelo gerencial proposto pelo governo federal, efetivou-se no Brasil o processo de desresponsabilização dos serviços básicos do Estado previstos na constituição, transferindo-os para a sociedade. Implementando as parcerias público-privado, cultuando-se os conceitos de accountability. Com base na administração gerencial, o governo brasileiro redefiniu seus principais setores de atuação, afetando o regime de colaboração na educação, ao responsabilizar prioritariamente estados e municípios por sua oferta via descentralização municipal (municipalização da educação). 
Com a instituição do PAR pelo governo federal no ano de 2007, os subgovernos ficaram reduzidos em sua importância como formuladores de políticas públicas. Aparecem como implementadores de políticas de um governo central que, no momento, não se mostra constrangido pelos outros entes federados. Há na divisão de poder e autoridade propostos pelo PAR a convivência de vários centros de poder representados pelos três entes, mas que possuem capacidades desiguais; fazendo os subgovernos tomarem o PAR enquanto espaço de negociação política (barganhas constantes para influenciar decisões que afetam seus interesses). Embora o governo federal tenha centralizado as ações e decisões do PAR em suas mãos, não significa que os outros entes foram eliminados do jogo federativo.

Neste formato, o PAR apresenta pouca variedade democrática, sendo utilizado conforme as atuais políticas gerenciais que reduzem o caráter de democracia da gestão educacional presente na Constituição (BRASIL, 2005) e na LDBEN ñ 9.394/1996 (BRASIL, 1996) da federação brasileira. Com a análise das normativas do PAR, constatamos seu caráter de consumerism (satisfação do cliente) como estratégia para tornar os subgovernos nacionais mais eficientes e eficazes por meio da gestão de resultados, operando a descentralização das ações, mas não dos recursos que devem ser gastos conforme o pactuado no menu de ações e subações.

Essa política está revestida da utilização do controle social, enquanto instrumento centralizador do Estado, na promoção do gerencialismo nas instituições de gestão da educação, como as Semeds, não se traduzindo em melhoria da qualidade escolar conforme propõe. $\mathrm{O}$ formato adotado no PAR contraria os princípios de um federalismo self rule plus shared rule, quando não assegura a capacidade da decisão conjunta dos subgovernos nacionais, para garantir benefícios próprios e comuns mútuos. O PAR é legitimado por um decreto [Decreto no 6.094/2007 (BRASIL, 2007a)] que normatiza as regras do jogo e centraliza o poder de decisão nas mãos da União. De outro lado, reconhece os poderes locais enquanto constituintes do pacto federativo por meio do regime de colaboração. Essa prerrogativa lança a perspectiva de que há a possibilidade de um federalismo mais equilibrado no Brasil.

A pequena autonomia que o PAR dá aos municípios na sua implementação reduz a possibilidade de utilização de mais recursos para o atendimento dos objetivos traçados no plano, logo, as Secretarias Municipais de Educação tornam-se meras executoras dessa política federal. A reorganização do PAR exige descentralização das ações, denotando ruptura com o modelo de poder vigente, fazendo os âmbitos horizontal e vertical interligarem-se para termos a centralidade da ação coordenada, um real federalismo coordenado com base nos argumentos expostos. 


\section{Cooperative federalism and Articulated Actions Plan (PAR) - some theoretical approaches}

\section{Abstract}

The article discusses Brazilian federalism from the theoretical matrix self rule plus shared rule, i.e. federalism as a pact. From this theoretical framework, it is argued that the educational policy is directed to streamline the federal pact in education through the collaboration scheme, now called Articulated Action Plan (PAR), and that it constitutes in fact a center constraining mechanism towards national sub governments where the Union stands as the great demos constraining of Brazilian federalism, characterizing an incomplete agreement.

Keywords: Cooperative federalism. Articulated Actions Plan. Federal pact.

\section{Federalismo cooperativo y Plan de Acciones Articuladas (PAR) - Algunos enfoques teóricos}

\section{Resumen}

El artículo discute el federalismo brasilero a partir de la matriz teórica self rule plus shared rule, o sea, el federalismo como pacto. A partir de esta matriz teórica, se defiende que la política educacional está encaminada a dinamizar el pacto federativo en el área educacional por medio del régimen de colaboración, por ahora denominado Plan de Acciones Articuladas (PAR), y que se constituye, en realidad, un mecanismo de center constraining a los subgobiernos nacionales donde la unión se sitúa como la grande demos constraining del federalimo brasilero, caracterizándose un pacto incompleto.

Palabras clave: Federalismo cooperativo. Plan de Acciones Articuladas. Pacto federativo. 


\section{Referências}

ABRUCIO, F. L. A coordenação federativa no Brasil: a experiência do período FHC e os desafios do governo Lula. Revista de Sociologia e Política, n. 24, jun. 2005.

. Os barões da Federação. São Paulo: USP/Hucitec, 1998.

ABRUCIO, F. L.; COSTA, V. M. F. Reforma do estado e o contexto federativo brasileiro. São Paulo: Fundação Konrad, 1998.

AFFONSO, R. B. A. O federalismo e as teorias hegemônicas da Economia do setor público na segunda metade do século XX: um balanço crítico. 2003. 268 p. Tese (Doutorado) - Universidade Estadual de Campinas, Campinas, 2003.

ARRETCHE, M. Estado federativo e politicas sociais: determinantes da descentralização. Rio de Janeiro: Revan, 2000.

. Federalismo e relações intergovernamentais no Brasil:

a reforma de programas sociais .Dados, v. 45, n. 3, p. 431-58, 2002.

https://doi.org/10.1590/S0011-52582002000300004

. Federalismo e políticas sociais no Brasil: problemas de coordenação e autonomia. São Paulo em Perspectiva, v. 2, n. 18, p. 17-26, 2004. https://doi.org/10.1590/S0102-88392004000200003

. Federalismo e políticas sociais no Brasil: problemas de coordenação e autonomia. São Paulo em Perspectiva, v. 18, n. 2, p. 17-26, 2005. https://doi.org/10.1590/S0102-88392004000200003

. Políticas sociais no Brasil: descentralização em um estado federativo. In: MEETING OF THE LATIN AMERICAN STUDIES ASSOCIATION, 1., 1996, Chicago, Illinois. Proceedings... Pittsburgh: LASA, 1996. p. 1-35.

BALL, S. J. Diretrizes políticas globais e relações políticas locais em educação. Currículo sem Fronteiras, v. 1, n. 2, p. 99-116, jul/.dez. 2001.

BRASIL. Constituição da República Federativa do Brasil. São Paulo: Vértice, 2005. . Lei $\mathrm{N}^{\mathrm{o}} 10.172$, de 9 de janeiro de 2001. Aprova o Plano Nacional de Educação e dá outras providências. Diário Oficial da União, 10 jan. 2001. . Lei $\mathrm{N}^{\mathrm{o}}$ . Lei $\mathrm{N}^{\circ}$ 9.394, de 20 de dezembro de 1996.

Estabelece as diretrizes e bases da educação nacional. Diário Oficial da União, 23 dez. 1996. 
BRASIL. Ministério da Educação. Plano de Metas Compromisso Todos pela Educação: guia prático de ações. Brasília, DF: Ministério da Educação, 2007b.

. Ministério da Educação. Fundo Nacional de Desenvolvimento da Educação. Resolução n ${ }^{\circ}$ 14, de 8 de junho de 2012 do FNDE. Estabelece os critérios para o apoio técnico e financeiro às redes públicas de educação básica dos Estados, Municípios e Distrito Federal, no âmbito do Plano de Ações Articuladas (PAR). Diário Oficial da União, 12 jun. 2012;Seção 1.

. Plano de Metas Compromisso Todos pela Educação: instrumento de campo. Brasília, DF: Ministério da Educação, 2007c.

. Plano de Metas Compromisso Todos pela Educação: orientações gerais para a aplicação dos instrumentos. Brasília, DF: Ministério da Educação, 2007d.

. Presidência da República. Decreto $n^{\circ} 6.094$, de 24 de abril de 2007a. Dispõe sobre a implementação do Plano de Metas Compromisso Todos pela Educação, pela União Federal, em regime de colaboração com Municípios, Distrito Federal e Estados, e a participação das famílias e da comunidade, mediante programas e ações de assistência técnica e financeira, visando a mobilização social pela melhoria da qualidade da educação básica. Diário Oficial da União, 25 abr. 2007a.

. Proposta de Emenda Contitucional No 173/95. Transformada na Emenda Constitucional no 19/1998. Diário do Congresso Nacional. Seção I. Brasília, 1995.

BURGESS, M. Comparative federalism: theory and practice. New York: Routledge, 2006.

CAMARGO, A. La federación sometida: nacionalismo desarrollista e inestabilidad democrática. In: CARMAGNANI, M. (coord.). Federalismos latinoamericanos: México, Brasil, Argentina. México, DF: Fondo de Cultura Económica,1993. p. 300-62. p. 300-62. (Estudios. Sección de obras de Historia).

CLARKE, J. et.al. Managing social policy. London: Sage, 1994.

CLARKE, J.; NEWMAN, J. The managerial state. London: Sage, 1997.

COSTA, V. M. F. Federalismo e relações intergovernamentais: implicações para a reforma da educação no Brasil. Educação e Sociedade, v. 31, n. 112, p. 729-48, jul.-set. 2010. https://doi.org/10.1590/S0101-73302010000300005 
DUARTE, M. R. T. Sistemas públicos de educação básica e relações intergovernamentais: a ação da união e a autonomia dos sistemas locais de ensino. 2003. 482 p. Tese (Doutorado) - Universidade Federal Fluminense, Niterói, 2003.

DYE, T. R. The policy consequences of intergovernmental competition. Cato Journal, .v. 10, n. 1 , p. 59-73, Spring/Summer 1990.

ELAZAR, D. J. Exploring federalism. Tuscaloosa: The University of Alabama Press, 1987. . Federalism: an overview. Pretoria: HSRC Publishers, 1995. . Federalism and the way to peace. Kingston: Institute of Intergovernmental Relations, 1994 (Refletions, n.13).

HAMILTON, A.; MADISON, J; JAY, J. O federalista. Belo Horizonte: Lider, 2003.

KUGELMAS, E.; SOLA, L. Recentralização/descentralização: dinâmica do regime federativo no Brasil dos anos 90. Tempo Social, v. 11, n. 2, p. 63-81, 2000. https://doi.org/10.1590/S0103-20701999000200005

LIJPHART, A. Patterns of democracy: government forms and performance in the thirty-six coutriens. New Haven: Yale University Press, 1999.

LUCE, M. B; MEDEIROS, I. L. Gestão democrática, UFRS. Porto ALEGRE/RS, 2006.

MINEIRO, A. S. Desenvolvimento e inserção externa: algumas considerações sobre o período 2003-2009 no Brasil. In: MAGALHÃES, J. P. A.

(Org). Os anos Lula: contribuições para um balanço crítico 2003-2010.

Rio de Janeiro: Garamond, 2010.

OLIVEIRA, T. O poder local e o federalismo brasileiro. Belo Horizonte: Fórum, 2010.

PIERSON, P. Increasing returns, path dependence, and the studies of politics. American Political Sciense Review, v. 94, n. 2, p. 251-67, June 2000. https://doi.org/10.2307/2586011

. The new politics of the welfare state. World Politics, v. 48, n. 2, p. 14379, jan. 1996.

RIKER, W. Federalism: origin, operation, significance. Little: Brown and Company, 1964. 
RODDEN, J. Comparative federalism and descentralization: on meaning and measurement. Comparative Politics, p. 481-500, july 2004.

SANO, H. Articulação horizontal no federalismo brasileiro: os conselhos de secretários estaduais. 2008. 308 p. Tese (doutorado) - Fundação Getúlio Vargas, São Paulo: 2008

SOUZA, C. Constitutional engineering in Brazil: the politics of federalism an decentralization. New York: St. Martin's Press, 1997.

. Federalismo e gasto social no Brasil: tensões e tendências. Lua Nova, n. 52, p. 5-28, 2001. http://dx.doi.org/10.1590/S0102-64452001000100002 . Federalismo, desenho constitucional e instituições federativas no Brasil pós-1988. Revista de Sociologia e Política, v. 24, p. 105-21, jun. 2005

SOUZA, M. C. C. Federalismo no Brasil: aspectos político-institucionais (1930-1964). Revista Brasileira de Ciências Sociais, v. 21, n. 61, p. 7-40, jun. 2006. https://doi.org/10.1590/S0102-69092006000200002

STEPAN, A. Toward a new comparative analysis of democracy and federalism: demos constraining and demos enabling federations. In: CONFERENCE ON FEDERALISM, DEMOCRACY, AND PUBLIC POLICY, 1999, Mexico, DF. Proceedings... Mexico, DF: Centro de Investigación y Docencia Económicas, 1999. p. 1-54.

WATTS, R. Contemporary views on federalism. In: VILLIERS, B. Evaluating federal systems. Dordrecht: Juta \& Co, 1994. p. 1-29.

WRIGHT, D. S. Del federalismo a las relaciones intergubernamentales en los Estados Unidos de America: una nueva perspectiva de la actuación reciproca entre el gobierno nacional, estatal y local. Revista de Estudios Políticos, n. 6, p. 5-28, 1978. . Intergovernmental relations: an analytical overview. Annals of the American Academy of Political and Social Science, v. 416, n. 1, p. 1-16, 1974. 


\section{Informações dos autores}

Karla Cristina Silva Sousa: Doutora em Educação pela Universidade Federal do Rio Grande do Norte (UFRN). Docente do Departamento de Educação II - UFMA. Contato: sousa.karla@ufma.br

Alda Maria Duarte Araújo Castro: Doutora em Educação pela Universidade Federal do Rio Grande do Norte (UFRN). Docente do Programa de Pós-Graduação em Educação - UFRN. Contato: aldacastro01@hotmail.com 